\title{
Konsumpcja mody a tożsamość. 0 społecznych funkcjach mody i zakupów modowych
}

DOI: 10.19195/2083-7763.9.7

\section{Wstęp}

Tożsamość człowieka to układ autodefinicji aktora społecznego, zintegrowany zbiór wyobrażeń, sądów i przekonań, które konstruuje on wobec samego siebie. Treść tych konstruktów jest wynikiem identyfikacji z określonymi wspólnotami i przyswojenia danych norm, wartości, ideologii, ale zarazem zawiera w sobie poczucie odrębności, niepowtarzalności własnego ja ${ }^{1}$. Tożsamość daje zarówno zakorzenienie, jak i poczucie jednostkowości. Definiowana jest poprzez to:

— co aktor powinien czynić i czym być, lub to, czego się po nim oczekuje, z odwołaniem do wizerunków jednostki, które przekazują jej inni,

- co jest związane z własnym, prywatnym sposobem bycia i działania,

- czym jednostka pragnie być, lub inaczej: wyobrażeniem tego, czym jest jednostka sama dla siebie ze względu na swą biografię i wartości, których broni, a także ze względu na swą sytuację aktualną i projekty².

Konsumpcja ma w dużej mierze charakter relacyjny ${ }^{3}$. Biorąc to pod uwagę, należy stwierdzić, że akt zakupu będzie wiązałludzi z tym, co inni myśląi robią. Ludzie, którzy nie urodzili się z wrodzonym zainteresowaniem modą i ze skłonnością do budowania różnic społecznych, będą musieli funkcjonować w społeczeństwie,

${ }^{1}$ Z. Bokszański, Indywidualizm a zmiana społeczna, Warszawa, 2007, s. 12.

2 Ibidem, s. 17.

${ }^{3}$ P. Aspers, J. Beckert, Introduction - value in markets, [w:] The Worth of Goods: Valuation and Pricing in the Economy, red. J. Beckert, P. Aspers, New York 2011, s. 3-41. 
w którym moda i różnice społeczne są uznawane i cenione $e^{4}$. Zwykle konsumpcja postrzegana jest jako względnie bierny wyraz przypisanej strukturalnie tożsamości - jej manifestacja i potwierdzenie (jak choćby w przypadku Bourdieu) albo też służy sprostaniu określonym, zakodowanym w kulturze - zwłaszcza przekazywanym przez reklamę - wizerunkom, kojarzonym z określonymi rolami i statusami (jak w wypadku dyskursu postmarksistowskiego). Można również w inny sposób ująć relacje pomiędzy konsumpcją a tożsamością: konsumując, tworzę i wyrażam prawdziwego siebie. W studiach kulturowych dostrzeżono, że poprzez określone formy konsumpcji jednostki realizują potrzebę identyfikacji, często sytuując się w opozycji do dominującej kultury. Polemiści Bourdieu argumentują, że wzory konsumpcji nie są prostym refleksem usytuowania w strukturze społecznej; jednostka jest zdolna do „urefleksyjnienia habitusu” ${ }^{5}$, co przekłada się na rozluźnienie związku między strukturą a tożsamością, dla której podstawą mogą być poszukiwania w dziedzinie konsumpcji.

\section{Ksztaltowanie się tożsamości poprzez konsumpcję mody}

Można postawić tezę, że w nowoczesnym społeczeństwie powszechne jest ocenianie jednostki poprzez jej ubiór. Wpływy ze świata mody tworzą wzór idealnego przedstawienia swojej tożsamości. Ten sposób nie jest jednak tak idealny, jak się wydaje. Należy bowiem pamiętać, że konstruowanie badania mającego na celu na przykład obiektywne i jednoznaczne rozstrzygnięcie, czy konsumenci są dziś manipulowani, czy wolni, czy konsumpcja narzuca, czy też pozwala samodzielnie odkrywać i budować tożsamość, jest o tyle problematyczne, że opierając się na tym samym materiale empirycznym, a odnosząc go do różnych koncepcji teoretycznych, łatwo uzasadnić każdą z odpowiedzi na powyżej stawiane pytania. Można natomiast zrekonstruować dyskursy, które doprowadziły do takich wniosków, i zaproponować sposoby nazywania, wartościowania, konceptualizowania zachowań konsumpcyjnych i traktowania podejmujących je aktorów ${ }^{6 ”}$. Ubranie nie jest postrzegane jako po prostu odbieranie danych aspektów jaźni, ale jest współkonstytuowaniem aspektów, takich jak tożsamość, seksualność i rola społeczna. Nasze ,ja” jest uzewnętrzniane przez to, co nosimy. Jako artefakt, odzież okrywa naszą fizyczność. Zatem manifestacja nas samych jest tłumaczona poprzez język wizualny. Ważne staje się pytanie o rolę ubioru $\mathrm{w}$ „budowaniu nas samych", czy jest to uzupełnienie naszego wyobrażenia o sobie lub przedłużenie

${ }^{4}$ P. Aspers, F. Godard, Sociology of fashion: Order and change, „Annual Review of Sociology” 39, 2013, s. 183.

${ }^{5}$ P. Sweetman, Twenty-first century disease? Habitual reflexivity or the reflexive habitus, „Sociological Review” 51, 2003, nr 4, s. 528-549; Ł. Iwasiński, Konsumpcja jako budowanie tożsamości, „Studia Socjologiczne" 2015, nr 4 (219), s. 176.

${ }^{6}$ Ł. Iwasiński, op. cit., s. 160. 
tego wyobrażenia? ${ }^{7}$ Wright zastanawia się nad znaczeniem ubioru i tego, co ludzie wykorzystują, kiedy cos na siebie zakładają. Czy ludzie próbują stworzyć obraz swojej wewnętrznej jaźni, aby inni mogli to zobaczyć lub stworzyć coś innego?

Poprzez nieodłączne elementy, takie jak smaki i wartości, wizerunek marek produktów modowych wyraża społeczny wizerunek, który konsument chce przekazać innym poprzez noszenie, używanie konkretnych marek odzieżowych i który pozwala mu na identyfikację ze szczególnym stylem życia grupy społecznej, do której należy lub chce przynależeć ${ }^{8}$. Da Costa Soares i Guedes twierdzą, że odzież, którą wybrała dana osoba, ma służyć przekazaniu osobistych upodobań i wizerunku społecznego, tak aby nie można było interpretować samej tożsamości przez patrzenie wyłącznie na ubiór. Wiktoriańskie kobiety przez modne ubrania chciały pokazać swój status społeczny ${ }^{9}$.

Badania zachowań i zwyczajów konsumentów obecnie opierają się na założeniu, że ludzie często kupują produkty nie dlatego, że do czegoś służą, ale dlatego, że coś symbolizują (dotyczy to zwłaszcza zakupów modowych). Nie oznacza to, że podstawowa funkcja produktu nie jest ważna, tylko że role, jakie produkty odgrywają w naszym życiu, rozciągają się poza funkcje użytkowe, które pełnią. Symboliczna funkcja konsumpcji nadaje głębsze znaczenie produktom, co może ułatwić wyróżnienie spośród innych, podobnych dóbr i usług - wszystkie rzeczy są równorzędne, a ludzie wybiorą tę markę, której wizerunek jest spójny z ich potrzebami. Przywiązanie na przykład do marek odzieżowych pomaga określić nasze miejsce $\mathrm{w}$ społeczeństwie, a wybory ułatwiają każdemu z nas nawiązywanie znajomości z ludźmi o podobnych upodobaniach ${ }^{10}$. Ubiór staje się formą uspołecznienia ${ }^{11}$. Potwierdzeniem jest teza Blumera, który głosi, że moda jest wyrazem gustu zbiorowego, ma znaczenie symboliczne, ustalane $w$ trakcie działań połączonych. W trakcie tych działań, polegających na przykład na oglądaniu wspólnie filmów, słuchaniu muzyki, uczestnictwie w tych samych wydarzeniach kulturalnych stanowiących inspirację dla mody, ludzie dokonują uprawomocnienia symboli, które stają się wyrazem wspólnych wartości. Pod wpływem tych doświadczeń zmienia się i rozwija smak kolektywny, którego wyrazem staje się nowa moda ${ }^{12}$. Wydaje się, że można przenieść tezę o działaniach połączonych na sytuacje zakupowe i zachowania konsumentek mody.

${ }^{7}$ L. Wright, What are we looking at? The photograph, clothing and identity. Art and design, „History and Theory” 6, 2009, s. 1-10.

${ }^{8}$ P. da Costa Soares, G. Guedes, Branding of fashion products: A communication process. A marketing approach, 2005, http:// businesscommunication.org/wpcontent/uploads/2011/04/25ABCEurope05.pdf (dostęp: 15.12.2018).

9 Ibidem.

${ }^{10}$ M.R. Solomon, Zachowania i zwyczaje konsumentów, przeł. A. Kasoń-Opitek, B. Sałbut, J. Sugiero, Gliwice 2006, s. 32.

${ }_{11}$ B. Dowgiałło, Ubieranie jako forma uspołecznienia, Gdańsk 2015.

12 H. Blumer, From class differentation to collective selection, „Sociological Quarterly” 3, 1969, s. $275-291$. 
Pojęcie konsumpcji ma bardzo szerokie znaczenie i nie ogranicza się obecnie jedynie do aktu spożycia czy też zakupu dobra lub usługi, zwłaszcza w odniesieniu do mody. „Konsumpcja dóbr jest widoczną częścią kultury. Zostają ustalone perspektywy i hierarchie, które grają istotną rolę w pełnym wachlarzu dyskryminacji, do jakich zdolny jest ludzki umys»"13. Potwierdzeniem powyższej tezy są także definicje łączące w sobie zagadnienia konsumpcji ze sferami tożsamości człowieka.

Konsumpcję można ująć z perspektywy antropologicznej jako zestawienie znaków, które konsument łączy ze sobą, by odzyskać poczucie tożsamości przez nadawanie im za pomocą projekcji subiektywnego znaczenia. Konsumpcja nie jest już rozpadem ani użytkowaniem rzeczy, lecz raczej konstruowaniem „ja" ${ }^{\prime 4}$.

Na współczesnych konsumentów możemy spojrzeć z co najmniej dwóch punktów widzenia. Po pierwsze, jako na poszukiwaczy i twórców tożsamości osobistej, którzy za pośrednictwem rynku jako znaczącego źródła mitycznych i symbolicznych zasobów konstruują narracje tożsamości, fabrykują spójne czy zróżnicowane i często sfragmentaryzowane poczucie jaźni, nierzadko odgrywając przy tym przypisane im scenariusze i dopasowując swoje tożsamości do imperatywów globalnego konsumeryzmu (ujęcie indywidualistyczne). Po drugie, konsumenci są traktowani jako producenci kultury (a nie tylko jej nosiciele), tworzący uczucia społecznej solidarności i ustanawiający odrębne, dobrowolne, a czasami chwilowe kulturowe światy poprzez poświęcanie się wspólnym konsumpcyjnym zainteresowaniom (problematyka subkultur, nowoplemion jako współczesnych, opartych na wolnym wyborze, wspólnot stylu życia) ${ }^{15}$. Tendencje indywidualistyczne i trybalne znajdują wyraz we współczesnym rynku mody, która jako zjawisko kulturowe zasadza się na łącznym występowaniu procesów dyferencjacji i naśladownictwa. Simmel pisze, że moda to

naśladownictwo danego przykładu, zaspokajające pragnienie adaptacji społecznej: wiedzie jednostkę drogą, którą podróżują wszyscy, dostarcza ogólnych przesłanek sprawiających, że zachowanie każdej jednostki staje się kolejnym przykładem [...]. Zatem moda stanowi po prostu jedną $\mathrm{z}$ wielu form życia, za pomocą których staramy się połączyć w jednolitej sferze działalności tendencję ku społecznemu ujednolicaniu i pragnienie jednostkowego odróżniania się i zmiany ${ }^{16}$.

${ }^{13}$ Douglas M., Isherwood B., The World of Good: Thowards an Anthropology of Consumption, London 1979, s. 66.

${ }^{14}$ M. Featherstone, Koncepcje kultury konsumenckiej, [w:] Zachowania konsumenta. Koncepcje i badania europejskie, red. M. Lambkin, G. Foxall, F. Raaij, B. Heilbrunn, Warszawa 2001, s. 301-302.

15 E.J. Arnould, C.J. Thompson, Consumer culture theory (CCT): Twenty years of research, "Journal of Consumer Research" 31, 2005, nr 4, s. 868-882; B. Cova, The postmodern explained to managers: Implications for marketing, „Business Horizons” 39, 1996, nr 6, s. 15-23; A. Kacprzak-Choińska, Indywidualistyczne i plemienne aspekty zachowań konsumenckich, [w:] Marketing przyszłości. Trendy. Strategie. Instrumenty. Przedsiębiorstwo i konsument w ewoluującym otoczeniu, „Zeszyty Naukowe Uniwersytetu Szczecińskiego” 2011, nr 661.

${ }^{16}$ G. Simmel, Philosophie der Mode („Moderne Zeitfragen” 1905, nr 11), red. H. Landsberg, Berlin 1905, s. 5-41. Unter dem Titel „Die Mode” wieder abgedruckt in: G. Simmel, Philosophische Kultur. Gesammelte Essais, Leipzig 1911, [w:] S. Magala, Simmel, Warszawa 1980, s. 182-183. 
Analiza mody Simmela pokazuje to, w jaki sposób człowiek może być częścią masy, bez utraty swojej indywidualności. Jego sugestia dotycząca konieczności „stylizowanego stylu życia” w nowoczesnym społeczeństwie może również być postrzegana jako dalszy rozwój tej samej idei dotyczącej roli, jaką odgrywają różne przedmioty konsumpcji w życiu współczesnego człowieka. Mimo że ich życie jest „stylizowane”, członkowie społeczeństwa są w stanie zachować pełną indywidualność i dzielić swój styl lub kilka stylów z innymi. Również bardziej współczesne badania mogą dowodzić słuszności stawianych przez Simmela tez ${ }^{17}$, albowiem

konsumowanie życia przez człowieka zostało podzielone na segmenty, rozbite na oddzielne etapy, które są powierzchownie połączone. System rynku kapitalistycznego urzeczywistnia różne wizerunki, które ludzie nabywają, konsumując te same produkty i przyjmując ten sam wzór konsumpcji reprezentowany przez te produkty [...]. Tak więc wydaje się, że różnica na poziomie kultury symbolicznej okazuje się być podstawową spójnością ${ }^{18}$.

Moda, analogicznie jak wszystkie podobne „samounifikujące się procesy społeczne", ma tendencję do obiektywizowania i rutynizacji. Zaczyna przypominać formalny schemat. W związku $\mathrm{z}$ tym konsumenci mogą odczuwać zmęczenie syzyfową pracą związaną ze zmiennością mody, przez co czują się nieustannie zmuszani do zakupu nowych rzeczy. Może się to jednak zdarzyć tylko wtedy, gdy moda będzie wiecznie powtarzalna ${ }^{19}$. „Nowy” nie byłby wtedy naprawdę nowy i nie byłby w stanie oczarować i uwieść konsumenta ${ }^{20}$.

Należy także zauważyć silny związek pomiędzy narodzinami konsumpcjonizmu a używaniem odzieży do ustalania tożsamości osoby ją noszącej.

Aby uchwycić związek między rozwojem rynków masowych a procesem cywilizacyjnym, musimy wziąć pod uwagę kulturową siłę samego nowoczesnego konsumpcjonizmu, jako nośnika indywidualizacji i jako medium dla osobistego urzeczywistnienia reaktywnej samowiedzy ${ }^{21}$.

We współczesnym społeczeństwie konsumpcjonizm nadal odgrywa ważną rolę w kulturze i rozwija się wraz ze zjawiskami dekonsumpcji.

Rzeczywiście, tryby samokontroli, które kiedyś wywodziły się ze wspólnych działań w interakcjach społecznych i głęboko przeżytych lękach dotyczących sądów innych, są transponowane $\mathrm{z}$ tych interakcji na prywatne relacje $\mathrm{z}$ samym sobą, w których pośredniczą dyskursy konsumenckie i same produkty 22 .

17 J. Gronow, Taste and fashion: The social function of fashion and style, „Acta Sociologica” 36, 1993, s. 89-100.

18 A. Firat, The consumer in postmodernity, „Advances in Consumer Research” 18, 1991, s. 74.

${ }_{19}$ R. Mayntz, B. Nedelmann, Eigendynamische Soziale Prozesse. Anmerkungen zu einem analytischen Paradigm, „Kölner Zeitschrift für Soziologie und Sozialpsychologie” 39, 1987, nr 4, s. 648668; J. Gronow, op. cit., s. 99.

${ }^{20}$ A. Noro, Muoto, moderniseetjti ja ,kolmas'. Tutkielma Georg Simmelin sosiologiasta (Form, Modernity and the 'Third'. A Study of Georg Simmel's Sociology), Jyvaskyla 1991.

${ }^{21}$ S. Binkley, The civilizing brand: Shifting shame thresholds and the dissemination of consumer lifestyles, „European Journal of Cultural Studies” 1, 2009, s. 28.

${ }^{22}$ Ibidem, s. 24-25. 
Jak twierdzi Binkley, ważne jest, aby mieć relację z samym sobą i kupować rzeczy dla siebie, pamiętając, że może to prowadzić do „mrocznej ścieżki”, te osoby, które mają niską samoocenę i są nieustannie pod wpływem opinii innych ludzi. A „szukanie bezpieczeństwa poprzez wybory konsumenckie jest samo w sobie panoszącym się i niewyczerpanym źródłem niepewności"23.

W świecie, w którym dostępnych jest coraz więcej towarów, tożsamość staje się bardziej niż kiedykolwiek kwestią osobistego wyboru obrazu siebie. Coraz częściej osoby są zobowiązane do wyboru swojej tożsamości ${ }^{24}$, gdyż tożsamość nie jest nam dana raz na zawsze. Obecnie możemy ją samodzielnie konstruować. Można argumentować, że kultura konsumpcyjna przekształca życie społeczne w sposób indywidualistyczny, nawet gdy społeczności i sieci zbiorowej konsumpcji kształtują się wokół praktyk opartych na tych nowo zindywidualizowanych praktykach ${ }^{25}$. Ludzie kształtują swoje relacje i stosunki społeczne, mając na uwadze własną tożsamość. Ludzie nieustannie angażują się w projekty indywidualnego samopoznania i rozwoju osobistego, a wtedy społeczne zobowiązania tracą na znaczeniu ${ }^{26}$. Konstrukcja poczucia indywidualnej tożsamości opiera się zatem na akceptacji społecznej, a to rodzi centralny paradoks konsumpcji. „Indywidualność zależy od społecznego konformizmu, ponieważ walka o osobowość może być podtrzymywana tylko za pomocą środków intersubiektywnej wymiany"27. Dla wielu osób tworzących/konsumujących swoją tożsamość, bardzo istotne jest, co myślą o nich inni. Jeśli ich tożsamość nie "pasuje” do sposobu/stylu życia grupy społecznej, starają się „dopasować” do wymagań przez nią stawianych.

Ważne z punktu widzenia rozważań o tożsamości we współczesnej teorii socjologicznej jest pojęcie „reflexive self — ja refleksyjne”28, które argumentuje, że współcześnie jednostki muszą aktywnie konstruować sensowne, żywe i spójne poczucie własnej tożsamości poprzez realny wybór. Konsumpcja odgrywa kluczową rolę w kształtowaniu tej tożsamości, dając ludziom ów wybór. Konsumpcja wyzwala konsumentów od społecznej dominacji marketingu, oferując nową formę wolności, w której konsumenci wyrażają swoją indywidualność i tożsamość ${ }^{29}$. Tożsamość jest zatem czymś, co należy stworzyć samemu. To odpowiedzialność społeczna (reflexivity) jest tym, co powinno przełamać jeden z podstawowych chwytów marketingowych marek i wyrazić tożsamość poprzez odzież w dowol-

23 C. Rojek, The consumerist syndrome in contemporary society: An interview with Zygmunt Bauman, „Journal of Consumer Culture” 1, 2004, s. 291-312.

24 A. Warde, Consumption, identity formation and uncertainty, „Sociology” 28, 1994, nr 4.

25 U. Beck, E. Beck, Gernsheim, Individualization. Institutionalized Individualism and its Social and Political Consequences, [w:] S. Blinkley, op. cit., s. 22.

26 S. Brinkman, Identity as Self-Interpretation, „Theory Psychology” 1, 2008.

27 Z. Bauman, Modernity and Ambivalence, Ithaca 1991, s. 201.

28 U. Beck, A. Giddens, S. Lash, Modernizacja refleksyjna. Polityka, tradycja i estetyka w porządku społecznym nowoczesności, przeł. J. Konieczny, Warszawa 2009.

29 Z. Bauman, Wolność, przeł. J. Tokarska-Bakir, Kraków-Warszawa 1995. 
ny sposób (w taki, który jest odpowiedni dla danej jednostki) ${ }^{30}$. Chodzi o to, że do swobodnego ukształtowania tożsamości można wykorzystać różne rekwizyty i sam konsumpcjonizm.

We współczesnej literaturze można odnaleźć wiele odniesień wiążących konsumpcję właśnie z procesami tworzenia tożsamości, stąd już o krok od powiązania konsumpcji z modą. W toku rozwoju społeczno-gospodarczego

konsumenci zamieszkiwali świat wypełniony obiektami, które niosły wiadomości. W coraz to większym stopniu byli otoczeni przez obiekty niosące znaczenie, które mogły być odczytane tylko przez tych, którzy umieli odczytywać kod obiektów. Z potrzeby stawali się semiotykami w nowym medium, mistrzami nowego kodu. Pokrótce, coraz to większa liczba zachowań społecznych stawała się konsumpcyjna i w coraz to większym stopniu jednostka była podciągnięta pod rolę konsumenta ${ }^{31}$.

Można postawić tezę, że zachowania konsumenckie mają we współczesnych, wysoko rozwiniętych technologicznie globalnych społeczeństwach największe znaczenie dla jednostek. Konsumpcja odgrywa tę istotną rolę, ponieważ umożliwia transferowanie znaczeń przypisanych produktom i różnym działaniom użytkowników. Tworzenie i wyrażenie tożsamości jest jedną z potrzeb, które dziś spełnia konsumpcja.

Jednostka w coraz większym stopniu ma możliwość kreowania siebie poprzez konsumowane produkty, które niosą znaczenia. Ponadto musi dbać o swą adekwatność, nadążając przez cały czas za zmianami, czyli uwzględnić mechanizm mody w toku konstruowania siebie. Niezależnie od tego, czy podąży za modą, czy będzie chciała się jej przeciwstawić - produkt, styl życia czy tożsamość uznawane za modne będą stanowiły swoisty punkt odniesienia. Konsumowanie, nabywanie dóbr stało się najistotniejszym sposobem manifestowania określonego światopoglądu, pozycji społecznej i daje możliwość kreowania siebie w sposób niezwykle dowolny, niemal bez ograniczeń, choć wyłącznie z pewnej puli możliwych wyborów ${ }^{32}$. Jednocześnie należy zauważyć, że cechą współczesnej mody jest jej demokratyzacja powodująca zanikanie podziału klasowego w sferze ubioru i rozróżnianie między „konwencjonalnym” a „oryginalnym” a nie pomiędzy statusową „górą" i „dołem”, a sama moda staje się fantazją człowieka na swój własny temat. Każdy ubiór - niezależnie od woli noszącego - ma wartość estetyczną, służącą za wskaźnik indywidualności, podlegając ogólnej klasyfikacji jako konwencjonalny lub oryginalny ${ }^{33}$.

30 A. Beckett, A. Nayak, The reflexive consumer, „Marketing Theory” 8, 2008, nr 3, s. 299-317.

${ }^{31}$ G. McCraken, Culture and Consumption - New Approaches to the Symbolic Character of Consumer Goods and Activities, Bloomington 1998, s. 20.

32 U. Kluczyńska, Jak konsumpcja stała się osią naszej tożsamości, „Przegląd Pedagogiczny” 2009, nr 2, s. 29.

33 E. Wilson, Adorned in Dreams: Fashion and Modernity, London 2013; A. Reckwitz, Odkrycie kreatywności. O procesie społecznej estetyzacji, Warszawa 2017, s. 170. 
Zwrócenie uwagi na indywidualizację człowieka, próby takiego budowania własnego ,ja” poprzez odpowiednie outfity modowe, które odróżnią go od innych, powoduje, że nacisk norm kulturowych czy struktury na kształtowanie się tożsamości jest pomijany bądź mocno redukowany. Obecne działania marketingu modowego próbują wykorzystywać obydwie te strategie, co oznacza, że istnieją przekazy reklamowe zwracające uwagę na możliwość osiągnięcia określonego statusu społecznego na przykład poprzez wykorzystanie marek czy produktów używanych/reklamowanych przez celebrytów (zob: kultura celebrycka i branding) albo przez inne osoby o wysokim statusie społecznym lub produktów kojarzonych z określonym stylem życia ważnej dla konsumenta grupy. Istnieją również przekazy reklamowe, które komunikują, że tylko poprzez zakup/używanie jakiegoś produktu modowego jednostka może odkryć własne „ja” i ta wartość - cel - staje się przedmiotem aspiracji konsumentów.

\section{Kupowanie tożsamości przez zakupy modowe}

Krótka dyskusja odnosząca się do kształtowania się tożsamości przez konsumpcję mody jest dobrym elementem wprowadzającym do kwestii realizowanych zachowań konsumentów w sferze ubioru.

Zakupy [...] są sposobem, w jaki poszukujemy siebie i swojego miejsca w świecie. Choć dokonywane w miejscach jak najbardziej publicznych, są w swojej istocie intymnym i osobistym doświadczeniem. Kupować to smakować, dotykać, przebierać, rozważać i debatować nad tysiącami możliwości, próbując określić to, czego potrzebujemy bądź pragniemy. Kupować w sposób świadomy znaczy nie tylko poszukiwać na zewnątrz, w sklepie, ale także wewnątrz, wykorzystując pamięć i pragnienie. Zakupy są procesem interaktywnym, poprzez który prowadzimy dialog nie tylko z innymi ludźmi, z miejscami i przedmiotami, ale także z samymi sobą. Ten dynamiczny, choć równocześnie refleksyjny proces ujawnia i formuje części ja, które w innym przypadku pozostałyby uśpione ${ }^{34}$.

Z badań jakościowych przeprowadzonych techniką wywiadu swobodnego (IDI ${ }^{35}$ wśród młodych mieszkańców aglomeracji miejskiej wypływają istotne wnioski będące potwierdzeniem tezy o kształtowaniu tożsamości poprzez konsumpcję mody. $\mathrm{Z}$ wypowiedzi badanych wynika, że istnieją pewne strategie w wykorzystywaniu mody i jej konsumpcji do konstruowania własnego ja. Dalej przedstawione zostały pewne uniwersalne kryteria wybierania odzieży i funkcji kreowania tożsamości dzięki modzie:

${ }^{34}$ C. Campbell, Kupuję, więc wiem, że jestem. Metafizyczne podstawy nowoczesnego konsumery$z m u$, „Kultura Popularna” 4, 2006, nr 18, s. 51.

${ }^{35}$ Badania pod kierunkiem A. Perchli-Włosik i J. Wardzały prowadzone w Instytucie Socjologii Uniwersytetu Wrocławskiego na temat „Moda i przedsiębiorczość w opiniach młodych mieszkańców wielkiego miasta", 2018, N=40. 
- niewerbalne, komunikacyjne funkcje mody, zakupów i ubierania się "moda jako wizytówka”:

Jest ważna [moda - A.P.-W.], bo uważam, że przez modę możemy tak jakby, no tworzymy taką swoją wizytówkę, i pokazać się ze strony takiej niewerbalnej bym powiedziała, ponadto nie musimy z nikim rozmawiać, żeby spodziewać się po nim czegoś, kim on jest, co lubi, no czyli traktuję modę jako taką wizytówkę, co jest dla mnie dość ważnym elementem. (R1P)

— Moda i ubiór jako sposób na odróżnienie się od innych — indywidualizowanie, poczucie wyjątkowości:

Kieruję się tym [w trakcie zakupów - A.P.-W.], żeby były inne [ubrania - A.P.-W] i żeby nie były takie, jak ktoś już ma, żeby były takie „o jakieś dziwne!”. no takie ubrania mi się podobają. (R2P)

Wybrałam ten styl ubioru jeszcze jakiś czas temu, kiedy on nie był tak popularny, a teraz w każdej sieciówce można spotkać spodnie z wysokim stanem i ortalionowe kurtki, co już mi się miej podoba, więc no pewnie znowu nastąpi jakaś modyfikacja z tego względu. A to ja sobie znowu wrócę do pastelowych kolorów skoro nie są za modne za bardzo. (R2P)

Charakteryzuje mnie prostota stroju. Wyrażam tą prostotą siebie. Liczy się dla mnie prostota, ale przede wszystkim faktura i struktura wykonania (małe dzieła sztuki). Przy wyborze liczy się to, czy patrząc na rzecz, się nią zachwycam, czy nie jest to kolejna rzecz w szafie, której nie założę. (R1A)

- moda i ubiór jako sposób wyrażenia siebie, swojego osobistego stylu, swojej osobowości i jednocześnie zwrócenie uwagi na funkcje ograniczeń kulturowych i konformizm:

To, w co się ubieram, ma być wygodne, w moim stylu i przede wszystkim ma wyrażać moją osobowość. (R4F)

Moda jest dla mnie bardzo ważna, dlatego że poniekąd mogę tym wyrazić bardziej siebie, że po prostu można coś ze sobą innego przekazać i sądzę, że każdy nie powinien się bać wyrazić siebie i podążać serca i za głosem naszej osobistego stylu. Dużo ludzi się boi tego, bo boi się być oceniany. (R1F)

Co prawda dzisiaj mamy dużą swobodę wyboru, ale nie odważyłabym się ubrać dzisiaj różowego dresu, tak jak to się nosiło na początku 2000 roku. (R3F)

Ubieram rzeczy pod kątem tego, co do siebie pasuje, i co generalnie jest na topie, ale nie muszę mieć nowych laczków od Gucci, żeby czuć się modna, po prostu zwracam uwagę na to, co noszę i jak wyglądam. Wiadomo, nie narysuję sobie brwi od szklanki, bo teraz się już takich nie nosi, to nie jest 2001 rok i nikt już nie słucha Mandaryny [śmiech]. (R4F)

Kiedyś tak miałam na pewno, że bardzo się bałam tego, jak ludzie będą mnie postrzegać, tego typu, że nie pozwoliłam sobie wyjść w spodenkach i bokserce, no bo to nie reprezentuje w $100 \%$ mnie i w ogóle nie odróżnia mnie od reszty środowiska. (R2O) 
- moda i ubieranie się jako możliwość „bawienia się” wyborem własnej tożsamości:

Uważam modę za coś, co nam towarzyszy codziennie i to jest okazja, że skoro muszę sama sobie wybierać to, jak będę wyglądać i się prezentować, to jest to dobra okazja, żeby się tym pobawić, dlatego lubię przeglądać osoby, które właśnie tym się zajmują poważnie, tak jak szafiarki. (R1O)

- moda i ubieranie jako wyrażenie własnej osobowości bez poczucia ograniczeń społecznych i kulturowych, czyli „express yourself”:

Wychodzi ode mnie, nie czuję żadnej presji społecznej na sobie. Chcę dobrze wyglądać i lubię dobrze wyglądać, ubrania to jest też takie pokazywanie siebie i swojego charakteru, w myśl hasła "express yourself”. (R4O)

Co oczywiste, nie są to wszystkie sposoby kreowania i wyrażania własnej tożsamości przez badanych respondentów. Tę krótką analizę można potraktować jako przyczynek do dalszych badań nad problematyką tożsamości i jej konstruowania we współczesnym hiperrealnym, postmodernistycznym świecie kultury konsumpcji.

\section{Podsumowanie}

Dzięki konsumowaniu mody ludzie mogą wyrazić swoje prawdziwe „ja”. Określone formy konsumpcji umożliwiają jednostce samoidentyfikację, czasami w opozycji do dominującej kultury, choćby ze względu na potrzebę odróżnienia się. Widać to $\mathrm{w}$ badaniach nad konsumpcją mody i odzieży w Polsce, prowadzonej w ramach grantu badawczego "Społeczny i ekonomiczny wymiar marki w sektorze mody" oraz w badaniach prowadzonych przez samą autorkę od 2011 roku ${ }^{36}$. Perspektywa konsumpcji mody jako kreatora tożsamości „koresponduje z panującą we współczesnej epoce indywidualizmu wizją (a w każdym razie jedną z dominujących wizji) człowieka, dla którego moralnym ideałem staje się autentyczność, a istotą życia - samorealizacja” ${ }^{37}$. „Ten indywidualistyczny dyskurs - w skrajnych przypadkach odrzucający, a w każdym razie spychający na daleki plan presję norm kulturowych czy struktury odnośnie do kształtowanie się tożsamości - może brzmieć nieco utopijnie" ${ }^{38}$.

Niemniej jednak z prowadzonych badań wynika, że bardzo często deklaratywnie ludzie traktują modę i jej konsumowanie jako metodę wyrażania siebie, własnej osobowości, stylu itp., co jest dość istotną konotacją tożsamościową.

${ }^{36}$ Por. J. Kall et al., Marka modowa. Jak zrozumieć konsumenta mody i stworzyć markę szyta na miarę?, Warszawa 2018; A. Perchla-Włosik, Moda jako komunikat w świetle teorii socjologicznych i badań empirycznych, „Zeszyty Prasoznawcze” 2015, nr 3 (323) i inne.

37 Z. Bokszański, op. cit, s. 62.

${ }^{38}$ Ł. Iwasiński, op. cit., s. 176. 


\section{Bibliografia}

Arnould E.J., Thompson C.J., Consumer culture theory (CCT): Twenty years of research, „Journal of Consumer Research" 31, 2005, nr 4.

Aspers P., Beckert J., Introduction - value in markets, [w:] The Worth of Goods: Valuation and Pricing in the Economy, red. J. Beckert, P. Aspers, New York 2011.

Aspers P., Godard F., Sociology of fashion: Order and change, „Annual Review of Sociology” 39, 2013.

Bauman Z., Konsumowanie życia, Kraków 2009.

Bauman Z., Modernity and Ambivalence, Ithaca 1991.

Bauman Z., Wolność, przeł. J. Tokarska-Bakir, Kraków-Warszawa 1995.

Beck U., Beck E.-Gernsheim, Gernsheim, Individualization. Institutionalized Individualism and its Social and Political Consequences, [w:] S. Binkley, The civilizing brand: Shifting shame thresholds and the dissemination of consumer lifestyles, „European Journal of Cultural Studies” 1, 2009.

Beck U., Giddens A., Lash S., Modernizacja refleksyjna. Polityka, tradycja i estetyka w porzadku społecznym nowoczesności, przeł. J. Konieczny, Warszawa 2009.

Beckett A., Nayak A., The reflexive consumer, „Marketing Theory” 8, 2008, nr 3.

Binkley S., The civilizing brand: Shifting shame thresholds and the dissemination of consumer lifestyles, „European Journal of Cultural Studies” 1, 2009.

Blumer H., From class differentation to collective selection, „Sociological Quarterly” 3, 1969.

Bokszański Z., Indywidualizm a zmiana społeczna, Warszawa 2007.

Brinkman S., Identity as Self-Interpretation. „Theory Psychology” 1, 2008.

Campbell C., Kupuję, więc wiem, że jestem. Metafizyczne podstawy nowoczesnego konsumeryzmu, przeł. M. Brzozowska-Brywczyńska „Kultura Popularna” 4, 2006, nr 18.

Costa Soares P. da, Guedes G., Branding of fashion products: A communication process. A marketing approach, 2005, http:// businesscommunication.org/wpcontent/uploads/2011/04/25ABCEurope05.pdf.

Cova B., The postmodern explained to managers: Implications for marketing, „Business Horizons” 39, 1996, nr 6.

Douglas M., Isherwood B., The World of Good: Thowards an Anthropology of Consumption, London 1979.

Dowgiałło B., Ubieranie jako forma uspołecznienia, Gdańsk 2015.

Featherstone M., Koncepcje kultury konsumenckiej, [w:] Zachowania konsumenta. Koncepcje i badania europejskie, red. M. Lambkin, G. Foxall, F. Raaij, B. Heilbrunn, Warszawa 2001.

Firat A., The consumer in postmodernity, „Advances in Consumer Research” 18, 1991.

Gronow J., Taste and fashion: The social function of fashion and style, „Acta Sociologica” 36, 1993.

Iwasiński Ł., Konsumpcja jako budowanie tożsamości, „Studia Socjologiczne” 2015, nr 4.

Kacprzak-Choińska A., Indywidualistyczne i plemienne aspekty zachowań konsumenckich, [w:] Marketing przyszłości. Trendy. Strategie. Instrumenty. Przedsiębiorstwo i konsument w ewoluującym otoczeniu, „Zeszyty Naukowe Uniwersytetu Szczecińskiego” 2011, nr 661.

Kall J., Perchla-Włosik A., Raciniewska A., Sempruch-Krzemińska K., Marka modowa. Jak zrozumieć konsumenta mody i stworzyć markę szytą na miarę?, Warszawa 2018.

Kluczyńska U., Jak konsumpcja stała się osią naszej tożsamości, „Przegląd Pedagogiczny” 2009, nr 2.

Lasota E., Moda, ciało, tożsamość a kontekst kulturowy. Forokonteksty, www.hueckel.com.pl/pl/ muzungu/servepdf?pdf...moda_cialo...full.

Mayntz R., Nedelmann B., Eigendynamische Soziale Prozesse. Anmerkungen zu einem analytischen Paradigm, „Kolner Zeitschrift fur Soziologie und Sozialpsychologie” 39, 1987, nr 4

McCraken G., Culture and Consumption - New Approaches to the Symbolic Character of Consumer Goods and Activities, Bloomington 1998.

Noro A., Muoto, moderniseetjti ja , kolmas'. Tutkielma Georg Simmelin sosiologiasta (Form, Modernity and the 'Third'. A Study of Georg Simmel's Sociology), Jyvaskyla 1991. 
Perchla-Włosik A., Moda jako komunikat w świetle teorii socjologicznych i badań empirycznych, „Zeszyty Prasoznawcze" 2015, nr 3 (323).

Reckwitz A., Odkrycie kreatywności. O procesie społecznej estetyzacji, Warszawa 2017.

Rojek C., The consumerist syndrome in contemporary society: An interview with Zygmunt Bauman, „Journal of Consumer Culture” 1, 2004.

Simmel G., Philosophie der Mode („Moderne Zeitfragen” 1905, nr 11), red. H. Landsberg, Berlin 1905.

Simmel G., Z psychologii mody. Studium socjologiczne, [w:] idem, Most i drzwi. Wybór esejów, Warszawa 2006.

Solomon M.R., Zachowania i zwyczaje konsumentów, przeł. A. Kasoń-Opitek, B. Sałbut, J. Sugiero, Gliwice 2006.

Sweetman P., Twenty-first century disease? Habitual reflexivity or the reflexive habitus, „Sociological Review" 51, 2003, nr 4.

Wright L., What are we looking at? The photograph, clothing and identity. Art and design, „History and Theory" 6, 2009.

Warde A., Consumption, identity formation and uncertainty, „Sociology” 28, 1994, nr 4.

Wilson E., Adorned in Dreams: Fashion and Modernity, London 2013.

\section{Fashion consumption and identity. Social functions of fashion purchases}

\section{Summary}

Social consumption and related phenomena can be seen in a variety of ways. The purchase of a particular good, such as clothing, can be read as a result of a fashion undertaking, a manifestation of social status, or activities to build a human identity.

The article has a theoretical and empirical nature and refers to the issue of constructing one's own identity by consuming fashion. It is an introductory element of the problem of consumer behavior in the sphere of clothing. The publication highlights the fact that individuals are definitely more involved now in creating their identity than they used to be. The first part of the article has the nature of sociological considerations and serves to find the paradigms most strongly associated with the construction of identity through consumption, in particular, fashion consumption. It also provides an overview of the most important sociological theories, both those created in the past and quite contemporary. In the second part, it refers to the results of qualitative research related to identity creation through fashion consumption. 